07

\title{
Плазмохимическое и жидкостное травление в постростовой технологии каскадных солнечных элементов на основе гетероструктуры GalnP/GalnAs/Ge
}

\author{
(C) А.В. Малевская, Ю.М. Задиранов, Д.А. Малевский, П.В. Покровский, Н.Д. Ильинская, В.М. Андреев
}

Физико-технический институт им. А.Ф. Иоффе РАН, Санкт-Петербург, Россия

E-mail: amalevskaya@mail.ioffe.ru

Поступило в Редакцию 30 июня 2020г.

В окончательной редакции 19 октября 2020 г.

Принято к публикации 19 октября 2020г.

\begin{abstract}
Проведены исследования и разработана технология формирования разделительной меза-структуры при создании каскадных солнечных элементов на основе гетероструктуры $\mathrm{GaInP} / \mathrm{GaInAs} / \mathrm{Ge}$. Исследованы методы травления слоев гетероструктуры: жидкостное химическое травление в составах на основе $\mathrm{HBr}$, $\mathrm{K}_{2} \mathrm{Cr}_{2} \mathrm{O}_{7}, \mathrm{H}_{2} \mathrm{O}$ и плазмохимическое травление в потоке рабочего газа $\mathrm{BCl}_{3}$. Проведен сравнительный анализ методов травления. Разработаны защитные маски на основе слоя фоторезиста и $\mathrm{TiO}_{x} / \mathrm{SiO}_{2}$. Получены каскадные солнечные элементы с низкими значениями токов утечки (менее $10^{-7} \mathrm{~A}$ при напряжении $0.5-1 \mathrm{~V})$.
\end{abstract}

Ключевые слова: каскадный солнечный элемент, гетероструктура, травление, меза-структура.

DOI: 10.21883/PJTF.2021.03.50568.18446

Каскадные солнечные элементы (КСЭ) на основе гетероструктур $\mathrm{A}_{3} \mathrm{~B}_{5}$ являются одними из наиболее перспективных в солнечной фотоэнергетике за счет высоких значений КПД: достигнут мировой рекорд $47 \%$ для шестикаскадных элементов при 140-кратном концентрировании солнечного излучения (АМ 1.5) [1,2].

Постростовая технология изготовления КСЭ включает следующие технологические операции: проведение фотолитографии, нанесение слоев диэлектрических и контактных материалов, локальное травление слоев гетероструктуры с использованием изотропных и анизотропных методов травления [3]. Полупроводниковая гетероструктура на основе $\mathrm{GaInP} / \mathrm{GaInAs} / \mathrm{Ge}$ включает более 20 слоев (см. таблицу), которые обладают различными физико-химическими свойствами, что приводит к необходимости разработки технологии травления отдельных слоев структуры. В настоящей работе проведены исследования методов жидкостного химического и плазмохимического травления слоев гетероструктуры для разделения ее на чипы КСЭ с целью увеличения технологичности и воспроизводимости процесса травления, а также увеличения срока службы КСЭ.

Жидкостное химическое травление является широко распространенным методом по причине низкой стоимости используемого оборудования и большого выбора химических реактивов. К недостаткам метода следует отнести ухудшение качества поверхности за счет различия скоростей травления разных по химическим свойствам слоев, а также изотропность процесса травления, приводящую к снижению точности топологии КСЭ и надежности пассивации слоев, находящихся вблизи поверхности структуры.
Травление слоев гетероструктуры проводится через маску, обеспечивающую защиту фоточувствительной области элемента и омических контактов, с последующим использованием этой же маски для нанесения диэлектрического покрытия методом взрывной литографии. При проведении жидкостного химического травления используется однослойная маска фоторезиста толщиной 3-4 $\mu \mathrm{m}$, задубленная методом инфракрасного поэтапного нагрева до температуры $130^{\circ} \mathrm{C}$.

Для формирования мезы в гетероструктуре $\mathrm{GaInP} / \mathrm{GaInAs} / \mathrm{Ge}$ с использованием жидкостного химического травления были исследованы различные методики [4,5]:

- одностадийное травление слоев гетероструктуры и германиевой подложки в сильноразбавленном травителе на основе бромистоводородной кислоты и перекиси водорода $\left(\mathrm{HBr}: \mathrm{H}_{2} \mathrm{O}_{2}: \mathrm{H}_{2} \mathrm{O}\right)$;

- травление слоев гетероструктуры селективно до германиевой подложки в травителе на основе бихромата калия и бромистоводородной кислоты $\left(\mathrm{K}_{2} \mathrm{Cr}_{2} \mathrm{O}_{7}: \mathrm{HBr}: \mathrm{H}_{2} \mathrm{O}\right)$ с последующим травлением германиевой подложки в травителе на основе водного раствора церия и серной кислоты $\left(\mathrm{Ce}\left(\mathrm{SO}_{4}\right)_{2} \cdot 4 \mathrm{H}_{2} \mathrm{O}: \mathrm{H}_{2} \mathrm{SO}_{4}\right)$;

- травление слоев гетероструктуры в травителе на основе бихромата калия и бромистоводородной кислоты $\left(\mathrm{K}_{2} \mathrm{Cr}_{2} \mathrm{O}_{7}: \mathrm{HBr}: \mathrm{H}_{2} \mathrm{O}\right)$ с последующим травлением германиевой подложки в слабощелочном электролите на основе глицерина (глицерин:КОН: $\mathrm{H}_{2} \mathrm{O}$ ). Данный метод является наиболее воспроизводимым и надежным, поэтому он был выбран для проведения дальнейшего анализа технологии формирования меза-структуры.

Различие физико-химических свойств слоев гетероструктуры $\mathrm{A}_{3} \mathrm{~B}_{5}$ и германиевой подложки приводит к 
Состав гетероструктуры GaInP/GaInAs/Ge

\begin{tabular}{|c|c|}
\hline Слой & Описание \\
\hline $\begin{array}{l}n \text {-GaAs } \\
n \text {-AlInP } \\
n \text {-GaInP } \\
p \text {-GaInP } \\
p^{+}-(\mathrm{AlGa}) \mathrm{InP} \\
p^{++}-\mathrm{AlGaAs} \\
n^{++} \text {-GaInP } \\
n \text {-AlInP } \\
n \text {-GaInP } \\
n \text {-GaInAs } \\
p \text {-GaInAs } \\
p \text {-(AlGa)InP } \\
p^{++} \text {-AlGaAs } \\
n^{++} \text {-GaAs } \\
n \text {-(AlGa)InP } \\
\times 8 \text { Al }{ }_{0.9} \mathrm{GaAs} \\
\text { Al }{ }_{0.1} \mathrm{GaAs} \\
n \text {-GaInAs } \\
n \text {-GaInP } \\
p \text {-Ge-подложка с } \\
p \text {-n-переходом }\end{array}$ & $\begin{array}{l}\text { Контактный слой } n \text {-GaAs } \\
\text { Широкозонное окно GaInP-субэлемента } \\
\text { Верхний GaInP-субэлемент } \\
\text { Тыльный потенциальный барьер GaInP-субэлемента } \\
\text { Верхний туннельный диод } \\
\text { Гетеробарьер для верхнего туннельного диода } \\
\text { Широкозонное окно GaInAs-субэлемента } \\
\text { Средний GaInAs-субэлемент } \\
\text { Тыльный потенциальный барьер среднего GaInAs-субэлемента } \\
\text { Нижний туннельный диод } \\
\text { Гетеробарьер для нижнего туннельного диода } \\
\text { Брэгговский отражатель (8 пар) } \\
\text { Буферный слой } \\
\text { Широкозонное окно Ge-субэлемента } \\
\text { Нижний Gе-субэлемент }\end{array}$ \\
\hline
\end{tabular}

разнице в скоростях травления отдельных слоев при использовании перечисленных выше методов жидкостного химического травления. В результате на боковой поверхности меза-структуры наблюдается появление протравов и уступов. Зависимости скорости травления и профиля мезы от кристаллографического направления и плоскости травления не обнаружено (рис. 1,a). Сложный профиль мезы снижает качество защитных и изолирующих покрытий, наносимых на ее поверхность, что в дальнейшем приводит к возникновению токов утечки.

Альтернативным методом формирования меза-структуры является плазмохимическое травление [6,7]. В настоящей работе процессы плазмохимического травления проводятся в комбинированной плазме индуктивного и емкостного разряда (ICP/RIE). Преимуществом этого метода является анизотропность травления, что позволяет увеличить точность топологии КСЭ.

При проведении плазмохимического травления предъявляются особые требования к защитным маскам. Формируется однослойная маска фоторезиста толщиной 4-5 $\mu \mathrm{m}$, в ходе травления она разрушается и уменьшается ее толщина, что в свою очередь приводит к изменению профиля боковой стенки мезы и искажению ее геометрических размеров на $1-2 \mu \mathrm{m}$ (рис. $1, b)$. С целью увеличения стойкости маски можно использовать многослойные покрытия, например, на основе слоев $\mathrm{TiO}_{x}$ (при $x$, близком к 2) толщиной 20-30 nm, $\mathrm{SiO}_{2}$ толщиной 70-80 nm и фоторезиста толщиной 4-5 $\mu \mathrm{m}$. Слои $\mathrm{TiO}_{x} / \mathrm{SiO}_{2}$ обладают высокой устойчивостью к плазмохимическому травлению, при этом они используются в технологии изготовления КСЭ в качестве антиотражающего покрытия. Таким образом, формирование слоев защитной маски проводится без увеличения числа технологических операций. Изменение размеров меза-структуры на несколько микрометров не оказывает влияния на параметры КСЭ, что позволяет проводить травление как через однослойные, так и через многослойные маски. Однако использование слоев $\mathrm{TiO}_{x} / \mathrm{SiO}_{2}$ увеличивает надежность защитных функций маски.

Травление слоев гетероструктуры GaInP/GaInAs/Ge осуществлялось в плазме трихлорида бора $\left(\mathrm{BCl}_{3}\right)$ на установке плазмохимического травления STE ICP 200e (SemiTEq). Трихлорид бора имеет ряд преимуществ при травлении соединений $\mathrm{A}_{3} \mathrm{~B}_{5}$ : обладает меньшей токсичностью и меньшей химической активностью, чем чистый хлор, а также меньшей степенью полимеризации в условиях разряда, чем хлоруглеродные соединения, что предотвращает загрязнение оборудования и обрабатываемой структуры $[8,9]$.

Различие физико-химических свойств отдельных слоев гетероструктуры приводит к необходимости разработки режимов проведения процесса для обеспечения низкой селективности травления, низкой шероховатости поверхности мезы и высокой стойкости маски. С целью достижения данных требований были подобраны оптимальные режимы плазмохимического травления: мощность индуктивного источника $600 \mathrm{~W}$, мощность емкостного источника $100 \mathrm{~W}$, напряжение смещения $290 \mathrm{~V}$. Температура столика, на котором располагалась структура, 

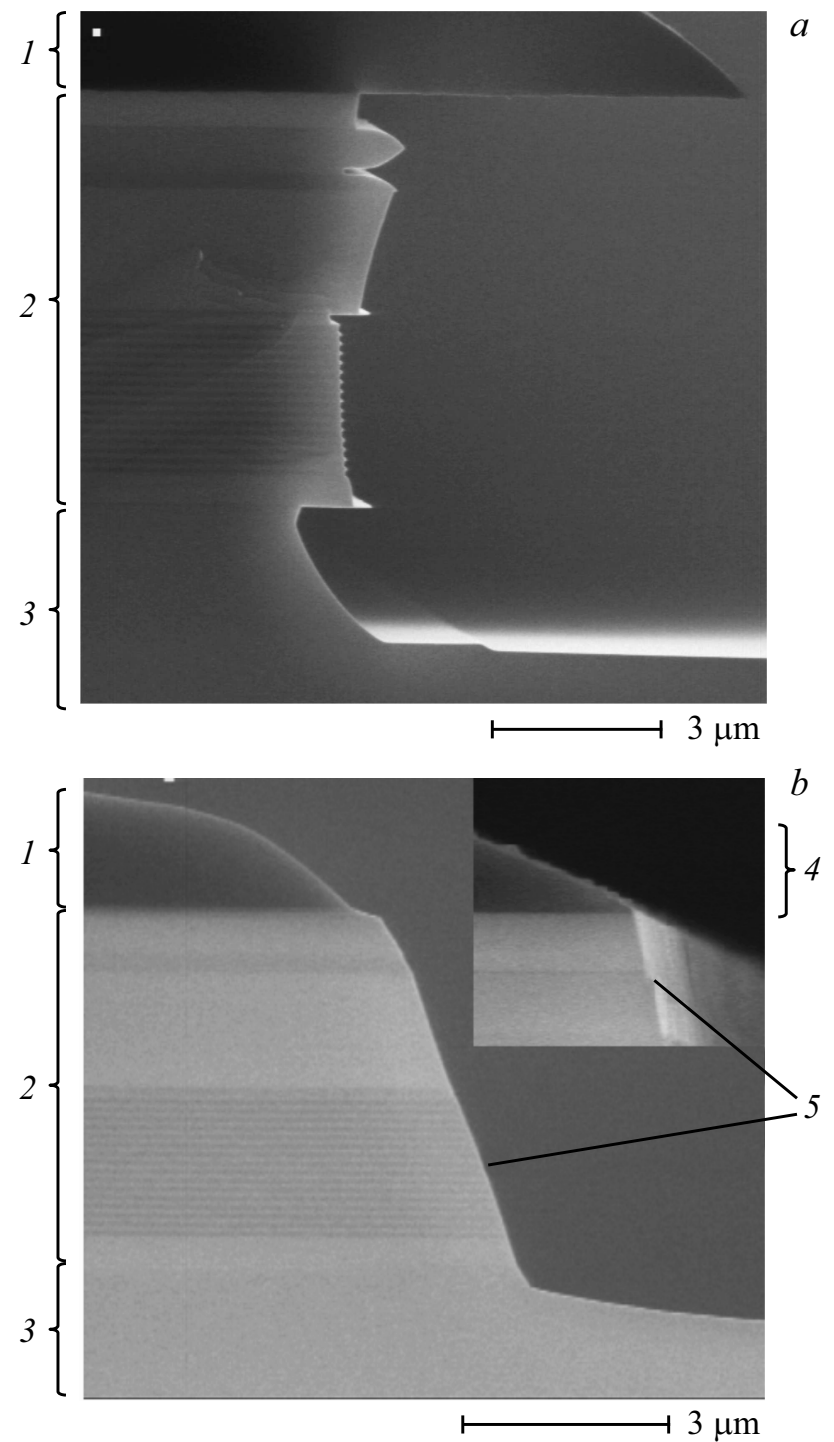

Рис. 1. Профили гетероструктуры $\mathrm{GaInP} / \mathrm{GaInAs} / \mathrm{Ge}$ после жидкостного химического травления в травителях $\mathrm{K}_{2} \mathrm{Cr}_{2} \mathrm{O}_{7}: \mathrm{HBr}: \mathrm{H}_{2} \mathrm{O}$ и глицерин:КОН: $\mathrm{H}_{2} \mathrm{O}$ через маску $(a)$ и после плазмохимического травления через маску $(b) .1-$ маска фоторезиста, 2 - гетероструктура, 3 - германиевая подложка, 4 - маска $\mathrm{TiO}_{x} / \mathrm{SiO}_{2} /$ фоторезист, 5 - боковая поверхность мезы.

составила $10^{\circ} \mathrm{C}$, что позволило избежать деформации защитной маски фоторезиста. Поток рабочего газа $\left(\mathrm{BCl}_{3}\right)$ $40 \mathrm{~cm}^{3} / \mathrm{min}$ обеспечил оптимальную скорость травления всех слоев гетероструктуры порядка $0.6-0.8 \mu \mathrm{m} / \mathrm{min}$ при давлении в рабочей камере $0.5 \mathrm{~Pa}$.

Травление гетероструктуры осуществлялось на глубину, превышающую суммарную толщину эпитаксиальных слоев гетероструктуры (порядка 5-6 $\mu \mathrm{m}$ ) на $1-4 \mu \mathrm{m}$, в германиевую подложку. Данные режимы травления обеспечили получение боковой поверхности мезы без селективных протравов благодаря выравниванию скоростей травления отдельных слоев гетероструктуры, а также за счет анизотропности травления, угол наклона боковой стенки зависит от параметров процесса и используемой маски (рис. $1, b)$. Ровный профиль мезаструктуры обеспечивает оптимальные условия для нанесения защитных и изолирующих покрытий на боковую поверхность мезы. Надежная защита мезы позволяет снизить воздействие параметров окружающей среды на КСЭ и увеличить срок их службы.

Для сравнения результатов технологических процессов создания разделительной мезы проведены измерения темновых и световых вольт-амперных характеристик (BAX) КСЭ на основе гетероструктуры GaInP/GaInAs/Ge, полученных при использовании технологии плазмохимического и жидкостного химического травления. На темновых ВАХ КСЭ, изготовленных с использованием метода жидкостного химического травления, наблюдается возрастание токов утечки в диапазоне $10^{-8}-10^{-7} \mathrm{~A}$ при напряжении $U=0.5-1 \mathrm{~V}$ на большинстве исследованных элементов. В КСЭ, изготовленных с использованием технологии плазмохимического травления, значения токов утечки составляют менее $10^{-9}$ А при $U<1 \mathrm{~V}$ (рис. 2), а в рабочем диапазоне напряжений $U=1.5-3 \mathrm{~V}$ токи прямого смещения приблизительно одинаковы. На изменение токов утечки при использовании разных методов травления влияет качество и состояние боковой поверхности мезы КСЭ. Также исходя из темновых ВАХ КСЭ можно отметить высокую однородность и воспроизводимость параметров при изготовлении серии элементов с использованием плазмохимического метода травления мезы, что является существенным преимуществом при обработке пластин большой площади.

При анализе световых ВАХ (рис. 3) КСЭ на основе гетероструктуры $\mathrm{GaInP} / \mathrm{GaInAs} / \mathrm{Ge}$ сделан вывод о незначительном влиянии каналов утечки, о чем свидетельствует малый угол наклона горизонтальной составляющей $\mathrm{BAX}$ в диапазоне напряжений 0-2.6 V.

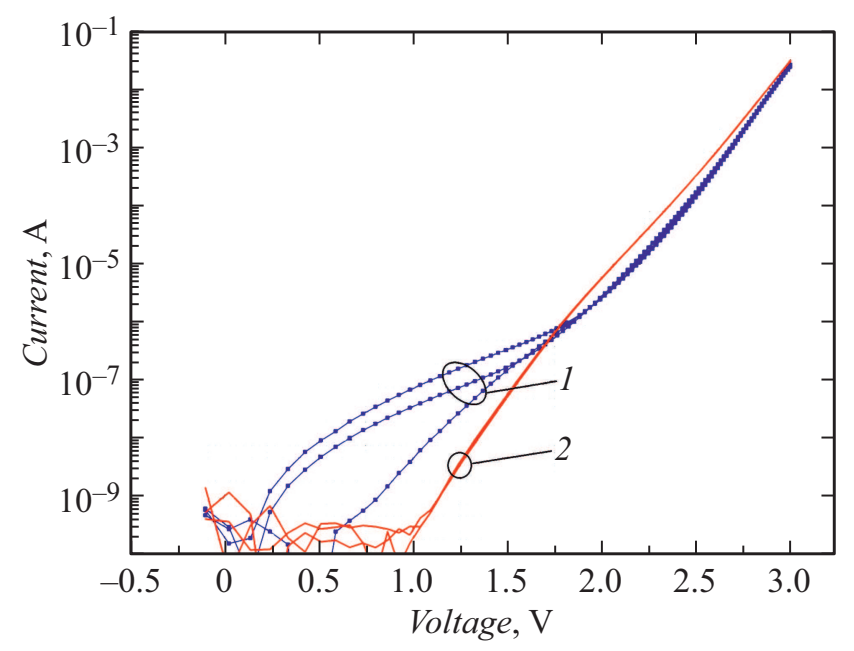

Рис. 2. Темновые вольт-амперные характеристики КСЭ после создания разделительной меза-структуры методами жидкостного химического (1) и плазмохимического (2) травления. 


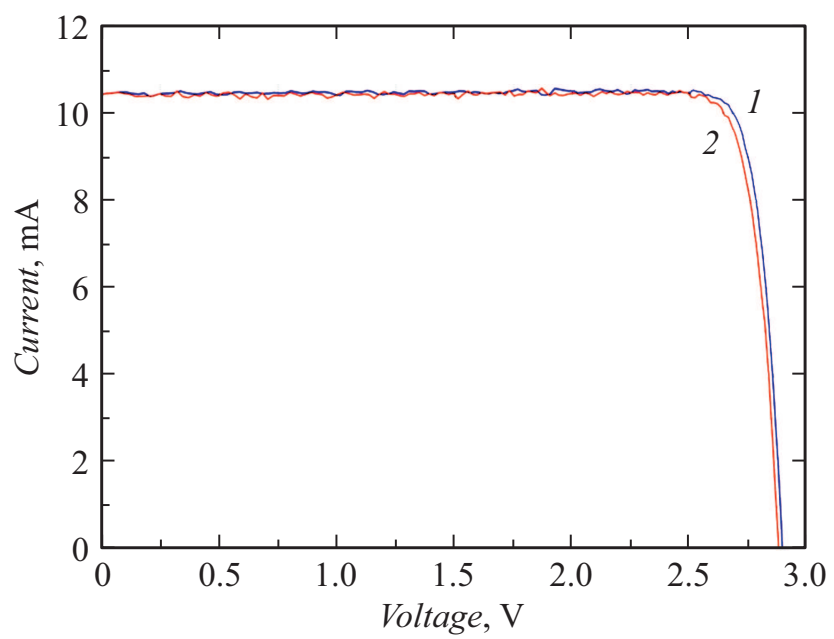

Рис. 3. Световые вольт-амперные характеристики (АМ 1.5, 10Х) КСЭ после создания разделительной меза-структуры методами жидкостного химического (1) и плазмохимического (2) травления.

Фактор заполнения $(F F)$ ВАХ составил $89.3 \%$ для КСЭ, изготовленных с использованием технологии плазмохимического травления, и 89.9\% для КСЭ с применением жидкостного химического травления для формирования разделительной меза-структуры. Значения $F F$ ВАХ более $89 \%$ свидетельствуют о высоком качестве ростовой и постростовой технологий изготовления КСЭ.

Таким образом, проведены исследования и сравнительный анализ жидкостного химического и плазмохимического методов травления многослойных гетероструктур на основе GaInP/GaInAs/Ge для создания разделительной меза-структуры КСЭ. Рассмотрены преимущества и недостатки различных технологических процессов. Метод плазмохимического травления позволяет формировать ровную боковую поверхность мезаструктуры, обеспечивает возможность качественной пассивации мезы, показывает высокую степень воспроизводимости, что позволят достичь высокой технологичности процесса и увеличить срок службы КСЭ. Результаты исследований показали низкие значения токов утечки и высокие значения фактора заполнения ВАХ (более 89\%) исследуемых КСЭ, что свидетельствует о высоком качестве разработанной постростовой технологии изготовления КСЭ на основе гетероструктуры GaInP/GaInAs/Ge.

\section{Конфликт интересов}

Авторы заявляют, что у них нет конфликта интересов.

\section{Список литературы}

[1] M.A. Green, E.D. Dunlop, D.H. Levi, J. Hohl-Ebinger, M. Yoshita, A.W.Y. Ho-Baillie, Progr. Photovolt.: Res. Appl., 27 (7), 565 (2019). DOI: 10.1002/pip.3171
[2] Zh.I. Alferov, V.M. Andreev, V.D. Rumyantsev, in Concentrator photovoltaics, ed. by A. Luque, V. Andreev. Springer Ser. in Optical Sciences (Springer, Berlin-Heidelberg, 2007), vol. 130, p. 25-50. DOI: 10.1007/978-3-540-68798-6_2

[3] M.E. Levinshtein, Semiconductor technology (WileyInterscience, USA, 1997).

[4] А.В. Малевская, Н.Д. Ильинская, В.М. Андреев, Письма в ЖТФ, 45 (24), 14 (2019). DOI: $10.21883 /$ PJTF.2019.24.48795.17953

[5] Е.В. Контрош, А.В. Малевская, Н.М. Лебедева, Е.А. Гребенщикова, Л.В. Контрош, Н.Д. Ильинская, В.С. Калиновский, Альтернативная энергетика и экология, 19 (183), 70 (2015). http://dx.doi.org/10.15518/isjaee.2015.19.009

[6] Д.И. Соловецкий, Механизмы плазмохимического травления материалов. Энциклопедия низкотемпературной плазмы (Наука, М., 2000), кн. III.

[7] M. de Lafontaine, E. Pargon, C. Petit-Etienne, G. Gay, A. Jaouad, M.-J. Gour, M. Volatier, S. Fafard, V. Aimez, M. Darnon, Solar Energy Mater. Solar Cells, 195, 49 (2019). https://doi.org/10.1016/j.solmat.2019.01.048

[8] F.F. Chen, J.P. Chang, Lecture notes on principles of plasma processing (Kluwer/Plenum, N.Y., 2002).

[9] Т.В. Свистова, Лучевые и плазменные технологии (ВГТУ, Воронеж, 2016). 